Article

\title{
Study on an Optimal Strut-And-Tie Model for Concrete Deep Beams
}

\author{
Haitao Chen ${ }^{1,2}$ (D) Lai Wang ${ }^{1,2, *}$ and Jitao Zhong ${ }^{1,2, *}$ \\ 1 Shandong Key Laboratory of Civil Engineering Disaster Prevention and Mitigation, \\ Shandong University of Science and Technology, Qingdao 266590, China \\ 2 College of Civil Engineering and Architecture, Shandong University of Science and Technology, \\ Qingdao 266590, China \\ * Correspondence: wlkdtjxy@sina.com (L.W.); zhongjitao@126.com (J.Z.); Tel.: +86-0532-860-57650 (L.W.)
}

Received: 1 August 2019; Accepted: 29 August 2019; Published: 3 September 2019

\begin{abstract}
The optimal strut-and-tie models (STMs) of two typical irregular concrete deep beams were constructed using evolutionary structural optimization and compared with those of previous studies. The reinforced concrete deep beam specimens were cast according to the reinforcement designs guided by different STMs. Eight irregular concrete deep beam specimens were experimentally investigated under stepped loading, and the differences in the amount of steel used, the load-carrying capacity, and the failure pattern of the different specimens were analyzed. The results show that the optimal STMs proposed in this study have significant advantages in terms of cost-effectiveness and can simultaneously ensure the load-carrying capacity, delay the crack propagation of irregular concrete deep beams, and reduce the amount of steel used in structural members. Therefore, they have an important engineering application value for the reinforcement design of irregular concrete deep beams.
\end{abstract}

Keywords: concrete deep beam; strut-and-tie model; reinforcement design; experimental study

\section{Introduction}

As one of the main load-carrying structural members, reinforced concrete deep beams have been widely used in bridge structures, high-rise buildings, and underground structures. In response to the need for door and window openings or equipment pipelines, concrete deep beams are often designed as irregular deep beams with variable cross sections or with openings to meet the functional requirements more economically and reasonably [1]. In general, the stress distribution is uneven inside an irregular concrete deep beam, especially at the load points or near abrupt geometrical changes, where the stress distribution is disorderly and dense, causing the Bernoulli hypothesis to be obviously invalid and the design theory based on the plane section assumption to no longer be applicable. The strut-and-tie model (STM) method can be used for the design of concrete structures, especially the design of the disturbed stress distribution region (D-region), with very good engineering precision [2-4]. Chen et al. [5] and Novak et al. [6] constructed optimal STMs for concrete deep beams with variable cross sections and openings and concrete deep beams with rectangular openings according to ACI 318-02 [7]. They then tested the corresponding concrete deep beam specimens. Their results showed that the STM method can be used for the conservative design of irregular concrete deep beams. Ye and Meng [8] proposed a calculation method for the STM of reinforced concrete deep beams based on the STM method in ACI 318-05 [9] and the design formulas in the Chinese Code for Design of Concrete Structures (GB 50010-2002) [10]; their calculation results are more accurate in reference to the existing deep beam test results in the literature. To date, the STM method has been included in the specifications of such countries as the United States, Germany, and Canada [11-13]. 
STM is a type of truss-like model that conceptually simplifies a concrete structure based on the stressing mechanism. Specifically, STM simplifies the tensile stress region as a tie, the compressive stress region as a strut, and the connection between the tie and the strut as a nodal zone. As a result, it not only makes full use of the tensile properties of steel rebars and the compressive properties of concrete but also satisfactorily reflects the load transfer mechanism inside a concrete structure.

The construction of an accurate and reasonable optimal STM is not only the primary task of the design of concrete structures using the STM method, but a better choice for the reinforcement design of concrete structures. However, in the STM construction process, the analysis of the stress transfer in irregular concrete deep beams, especially in their D-regions, is often difficult, inefficient, and requires a designer's subjective experience, resulting in a somewhat arbitrary model. That is, different designers can construct different optimal STMs and can also design significantly different reinforcements for the same irregular concrete deep beam member. Xie and Steven [14] proposed an evolutionary structural optimization (ESO) method to construct the STM of a concrete member by obtaining the optimal topology through the gradual removal of inefficient materials. Later, to address the low optimization efficiency of the ESO method, Yang et al. [15] proposed a bidirectional ESO (BESO) method to both remove and add material elements in the optimization process; thus method has a better optimization efficiency but is unstable and prone to oscillation. Herranz et al. [16] improved the STM of Novak et al. [6] by using the homogenization topology optimization method and proposed the corresponding optimal STM, which has significant advantages in controlling the width of cracks and reducing the amount of steel used, as demonstrated by the test results. Victoria et al. [17] generated the optimum STM for corbels and concrete deep beams with openings using the isolines topology design (ITD) method and verified the validity of the optimal STM with existing test data. Muttoni et al. [18] noted that when constructing the optimal STM for concrete structures, it is necessary to repeatedly optimize and improve the STM. They then gave suggestions on how to obtain the optimum STM. Based on an existing STM, Ali and White [19] proposed a new STM that can minimize the amount of steel used in concrete deep beams by adjusting the position and number of struts and ties in the STM; they also introduced two design parameters, namely, a practical reinforcement design coefficient and a stress redistribution coefficient. Wang et al. [20] constructed two optimal STMs for the same simply supported concrete deep beam with an opening and designed the reinforcement using each STM. The validities of the two optimal STMs were then verified with finite element (FE) analyses.

A properly and reasonably designed STM can effectively reduce the amount of steel used while ensuring the load-carrying capacity of a structural member. In this study, the STMs of two typical irregular concrete deep beams (designated as Group A and Group B) were constructed based on the FE results and the optimal topology. Additionally, the optimal STMs for each group of irregular concrete deep beams were compared with the STMs previously constructed by other researchers. For each group of irregular concrete deep beams, a plain concrete deep beam specimen and a reinforced concrete deep beam specimen according to the reinforcement design and guided by the corresponding STM were cast and subjected to static tests. Based on the test results, the STMs for each group of irregular concrete deep beams were comprehensively evaluated.

\section{Experimental Design}

\subsection{Specimen Geometry}

The irregular concrete deep beam in Group A is a simply supported concrete deep beam with variable cross sections and openings and is subjected to a concentrated force at the beam top. Its geometrical dimensions, constraints, and loads are shown in Figure 1a. The beam has a length of $1143 \mathrm{~mm}$, a depth of $534 \mathrm{~mm}$, and a width of $65 \mathrm{~mm}$, and a design load $\mathrm{F}_{\mathrm{A}}$ of $40 \mathrm{kN}$. The irregular concrete deep beam in Group B is a simply supported concrete deep beam with an opening in the lower left of the beam and is subjected to a concentrated force on the right side of the beam top. 
Its geometrical dimensions, constraints, and loads are shown in Figure $1 \mathrm{~b}$. The beam has a length of $1270 \mathrm{~mm}$, a depth of $864 \mathrm{~mm}$, a width of $65 \mathrm{~mm}$, and a design load $\mathrm{F}_{\mathrm{B}}$ of $100 \mathrm{kN}$.

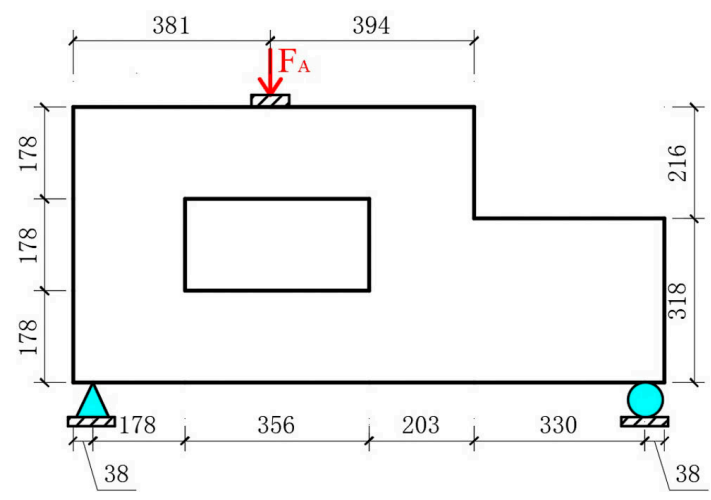

(a)

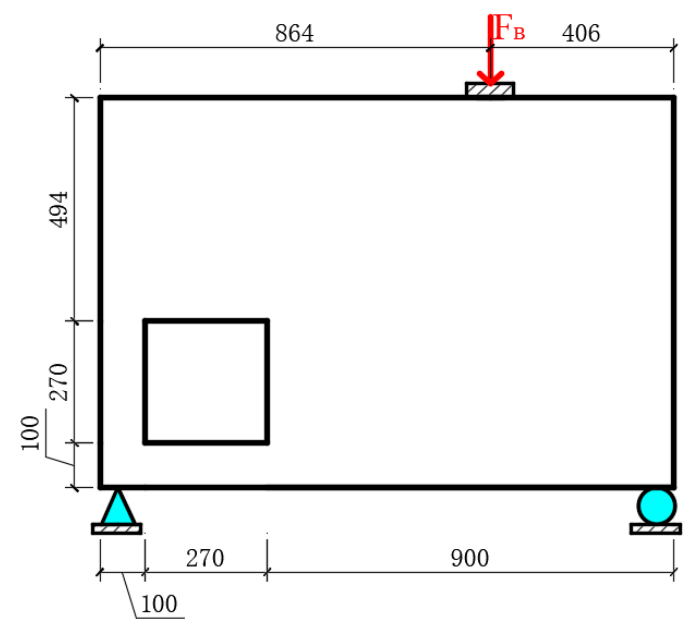

(b)

Figure 1. Geometry and dimensions of the irregular concrete deep beams: (a) Group A beam; (b) Group B beam (unit: $\mathrm{mm}$ ).

\subsection{STM Model Construction}

The optimal STM should fully reflect the load transfer mechanism of a structural member. To determine the load transfer path in an irregular concrete deep beam and understand the corresponding stress distribution and diffusion, a two-dimensional planar FEM was developed of the two groups of irregular concrete deep beam examples using ANSYS software. The analysis results are shown in Figures 2 and 3.

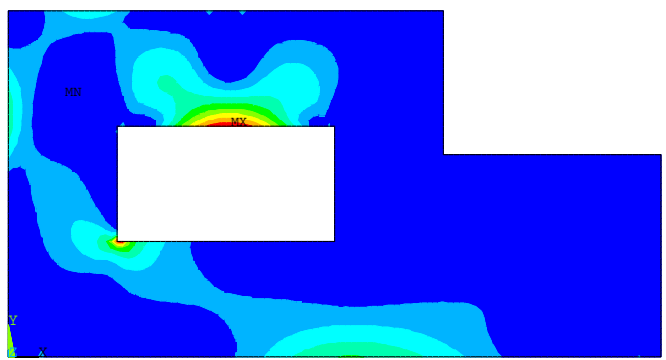

(a)

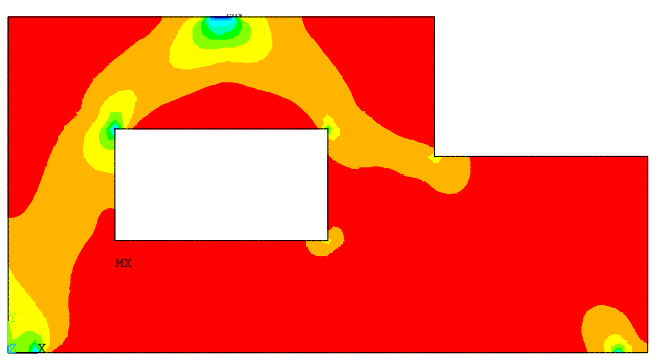

(b)

Figure 2. FE analysis results of Group A irregular concrete deep beams: (a) Principal tensile stress; (b) Principal compressive stress.

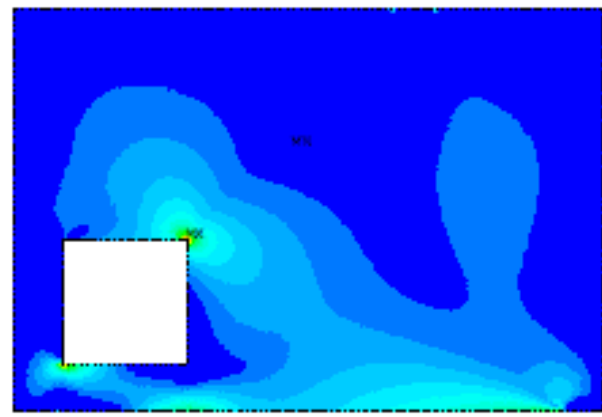

(a)

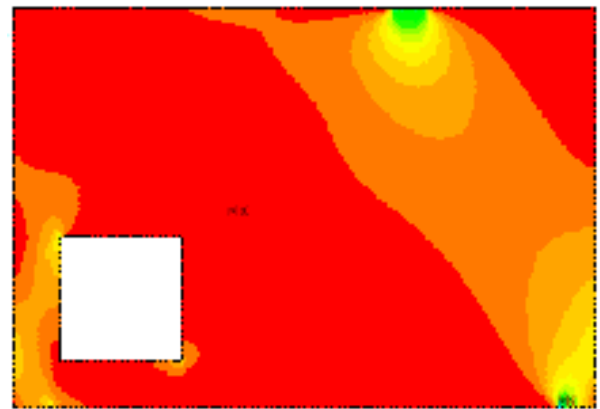

(b)

Figure 3. FE analysis results of the Group B irregular concrete deep beams: (a) Principal tensile stress (b) Principal compressive stress. 
It can be seen from Figure 2 that in the Group A irregular concrete deep beams, the principal tensile stress is high at the bottom of the beam midspan, the middle of the top of the opening, and the lower left corner of the opening. The tensile stress at the middle of the top of the opening is transferred diagonally to the upper left corner and to the upper right corner. The principal compressive stress at the loading point is transferred around the opening and diagonally toward the two end supports, the compressive stress is larger along the transfer path on the left side of the opening, and the compressive stress is concentrated at the corners of the opening, the concave corners of the variable cross sections, and the supports.

It can be seen from Figure 3 that, in the Group B irregular concrete deep beams, the tensile stress is high at the bottom of the beam and at the upper right and lower left corners of the opening, the tensile stress at the upper right corner of the opening diffuses diagonally to the left upper part and to the right support, and the tensile stress at the lower left corner of the opening is transferred to the left support and the bottom of the beam at the lower right of the opening. When the load at the top of the beam is transferred to both end supports, most of the compressive stress is transferred diagonally to the right support. As a result, the compressive stress is high at the loading point and at the right support. It is also relatively high on the left side and at the lower right corner of the opening.

To accurately and reasonably obtain the optimal STM, the BESO method was used to optimize the topology of each group of irregular concrete deep beams based on the aforementioned FE analysis [21,22]. The corresponding optimal topologies were obtained, as shown in Figure 4. Figures 5 and 6 show the stress contour plots of the two groups of irregular concrete deep beams with optimal topologies.

Based on the FE analysis results and the stress contour plots of the two groups of irregular concrete deep beams with optimal topology, the optimal STMs constructed in this study are shown in Figure 7 and are designated as STM A-04 and the STM B-04. In the figure, the solid line is the tie, the dashed line is the strut, and the circle is the joint.

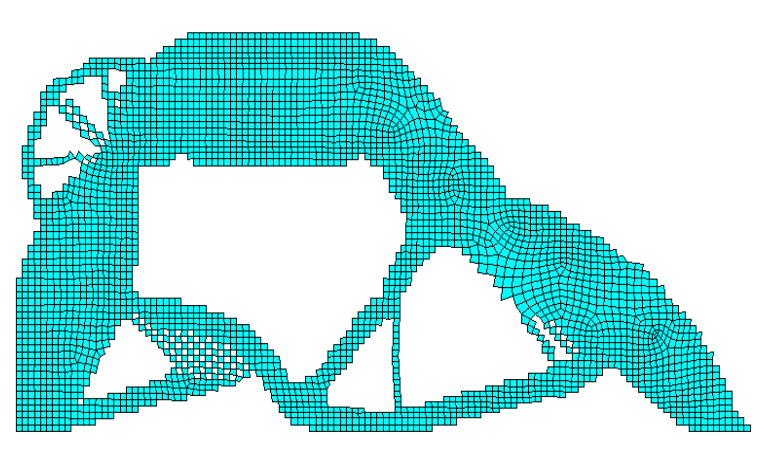

(a)

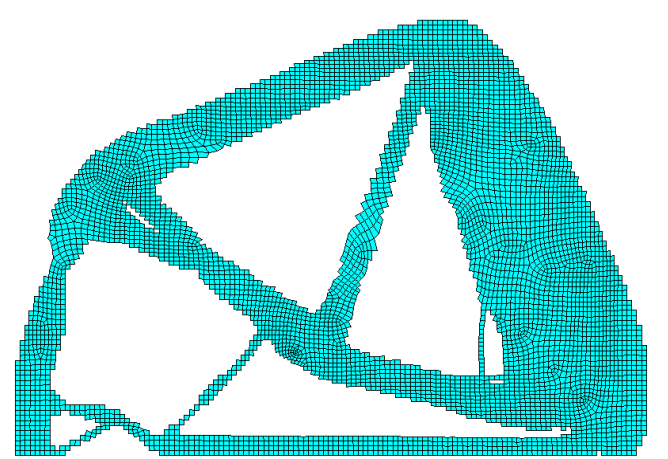

(b)

Figure 4. Optimal topology of the irregular concrete deep beams: (a) Group A beam; (b) Group B beam.

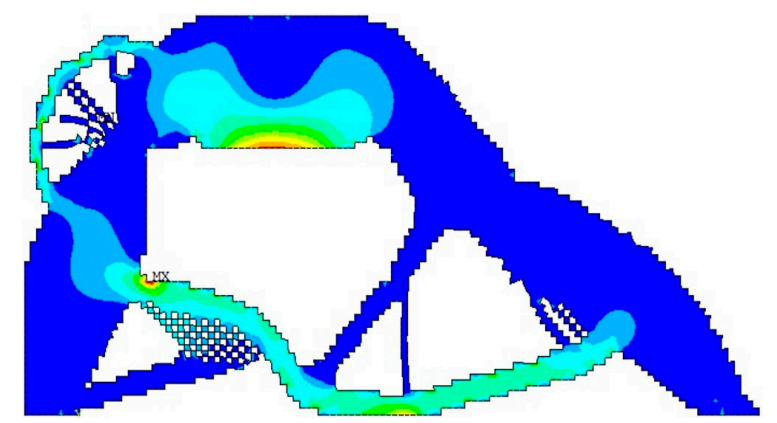

(a)

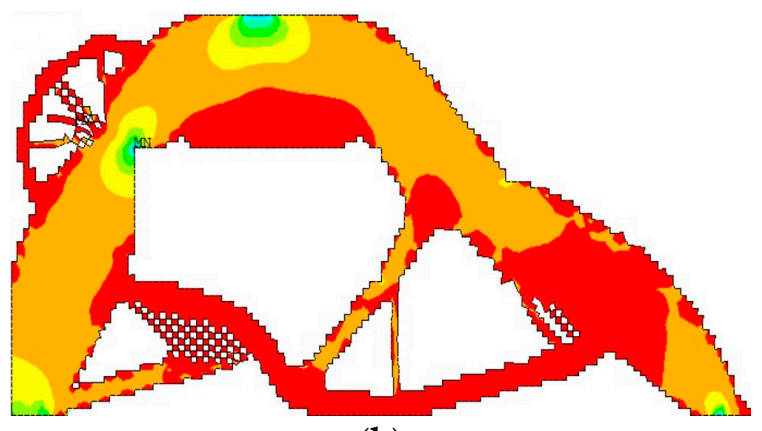

(b)

Figure 5. Stress contour plots of the Group A irregular concrete deep beams with optimal topology: (a) principal tensile stress; (b) principal compressive stress. 


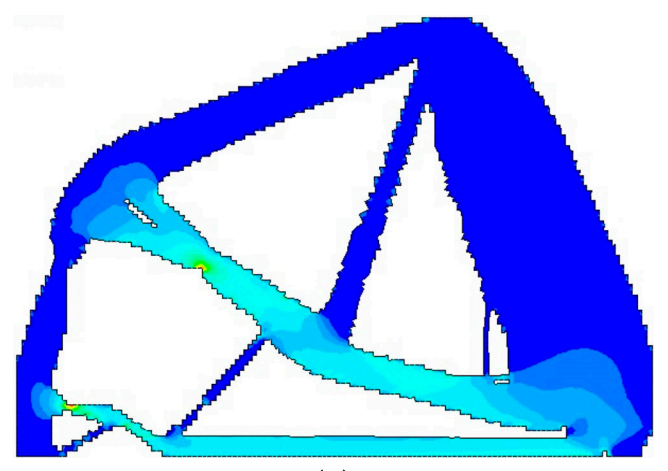

(a)

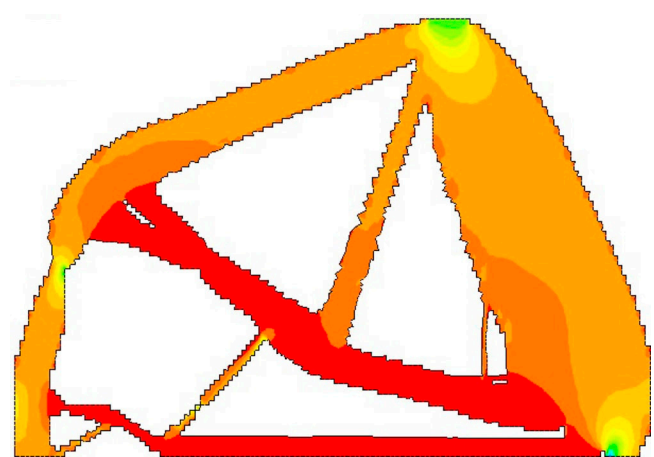

(b)

Figure 6. Stress contour plots of the Group B irregular concrete deep beams with optimal topology: (a) Principal tensile stress; (b) Principal compressive stress.

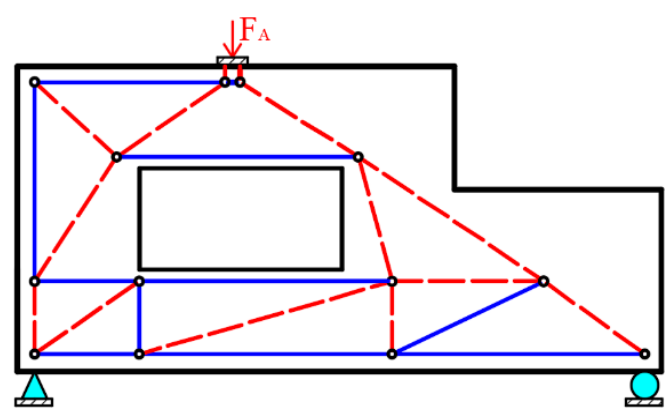

(a)

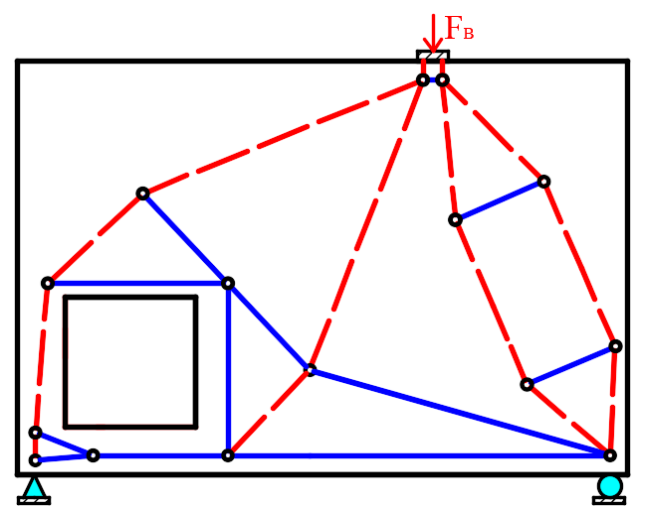

(b)

Figure 7. Optimal STMs proposed in this study: (a) STM A-04 and (b) STM B-04.

Several other researchers have also proposed their own optimal STMs for the two groups of irregular concrete deep beams investigated in this study and used those STMs to guide the reinforcement design. To facilitate a comparative analysis in this study, the two optimal STMs proposed by Ley et al. [23] for the Group A irregular concrete deep beams were selected, as shown in Figure 8. They are designated as STM A-02 and STM A-03, with the joints in the models omitted. The two optimal STMs proposed by Maxwell and Breen [24] for the Group B irregular concrete deep beams were selected, as shown in Figure 9, and are designated as STM B-02 and STM B-03, with the joints in this model also omitted.

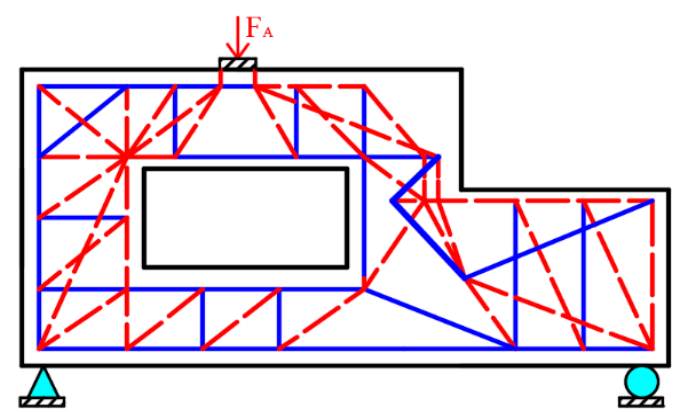

(a)

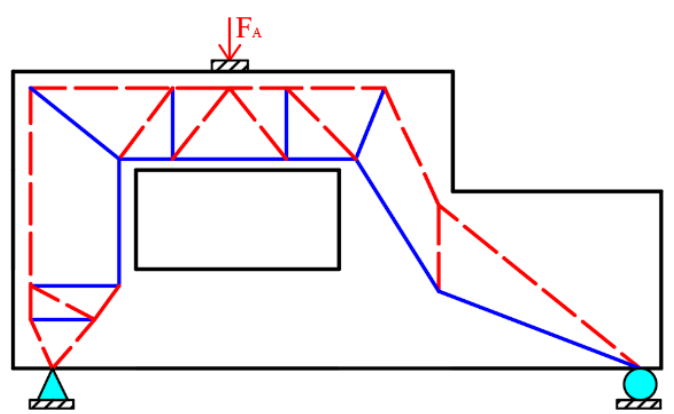

(b)

Figure 8. Optimal STMs proposed by Ley et al.: (a) STM A-02; (b) STM A-03. 


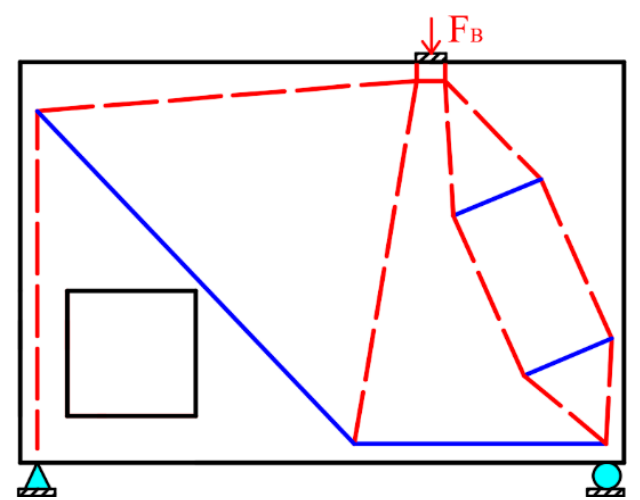

(a)

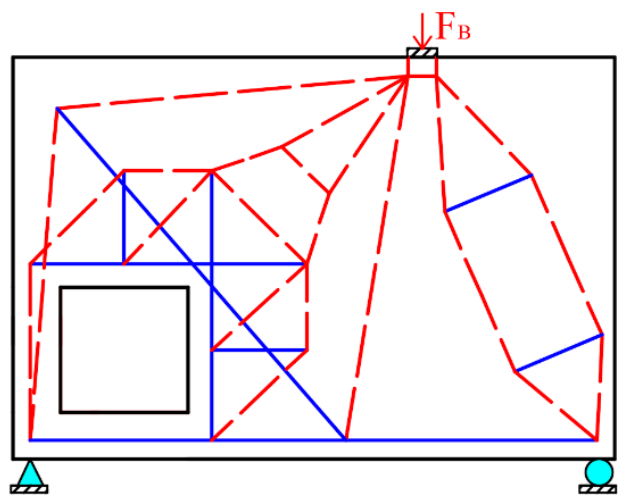

(b)

Figure 9. Optimal STMs proposed by Maxwell and Breen: (a) STM B-02; (b) STM B-03.

\subsection{Reinforcement Design}

Using the static truss analysis method, the bar members and joints in the optimal STMs of the irregular concrete deep beams were calculated and checked according to the relevant formulas in ACI 318-14 [25]. The resulting reinforcement designs are shown in Figures 10 and 11, where the reinforcement designs are designated consistently with their corresponding STMs.

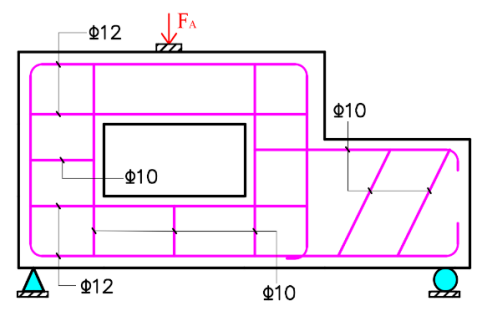

(a)

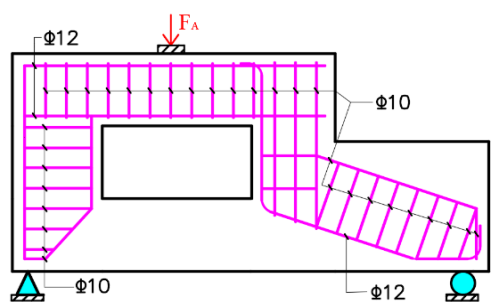

(b)

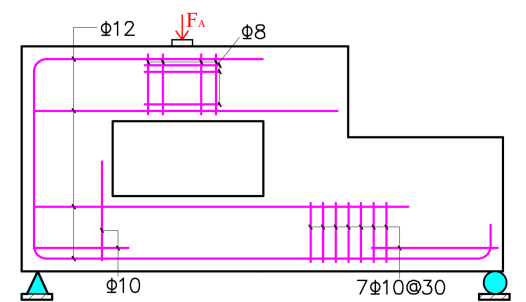

(c)

Figure 10. Different reinforcement designs of Group A beam: (a) Reinforcement design A-02;

(b) Reinforcement design A-03; (c) Reinforcement design A-04.

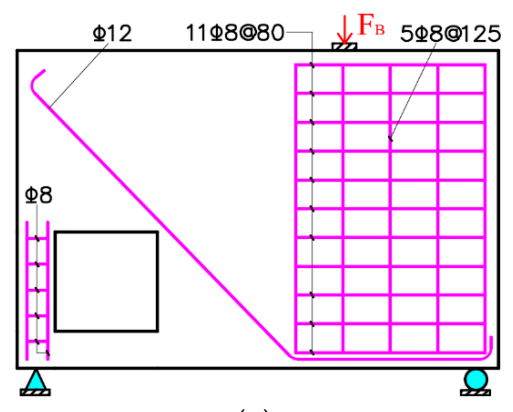

(a)

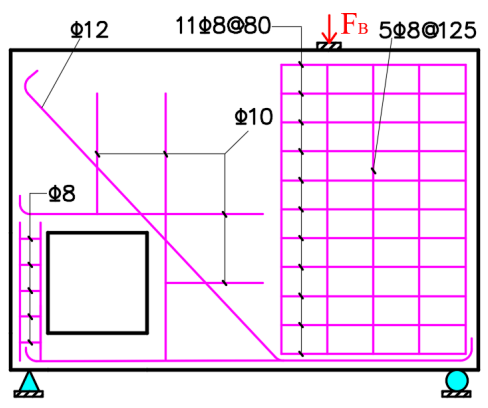

(b)

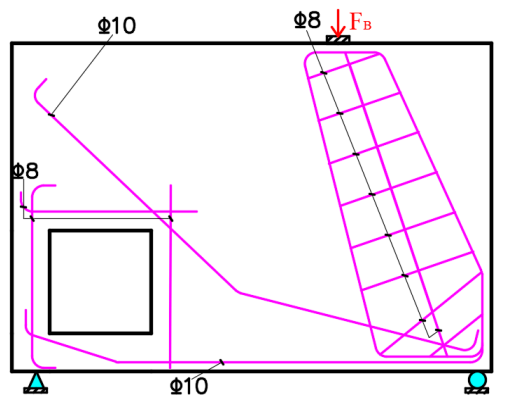

(c)

Figure 11. Different reinforcement designs of Group B beam: (a) Reinforcement design B-02; (b) Reinforcement design B-03; (c) Reinforcement design B-04.

\subsection{Specimen Preparation and Installation}

Considering their relatively small width $(65 \mathrm{~mm})$, the specimens were cast with C30 fine aggregate concrete, which was directly delivered to the casting site by a special concrete mixer truck. A hand-held concrete vibrator was used for vibrating during the casting process. At the same time, the corresponding concrete test cubes were reserved for the subsequent concrete material property tests. The frameworks and reinforcement cages of the two groups of irregular concrete deep beam specimens are shown in Figures 12 and 13. To facilitate a comparative analysis, two groups of irregular plain concrete 
deep beam specimens were also prepared and are designated as specimen A-01 and specimen B-01. The designations of other specimens correspond to those of their respective reinforcement designs.

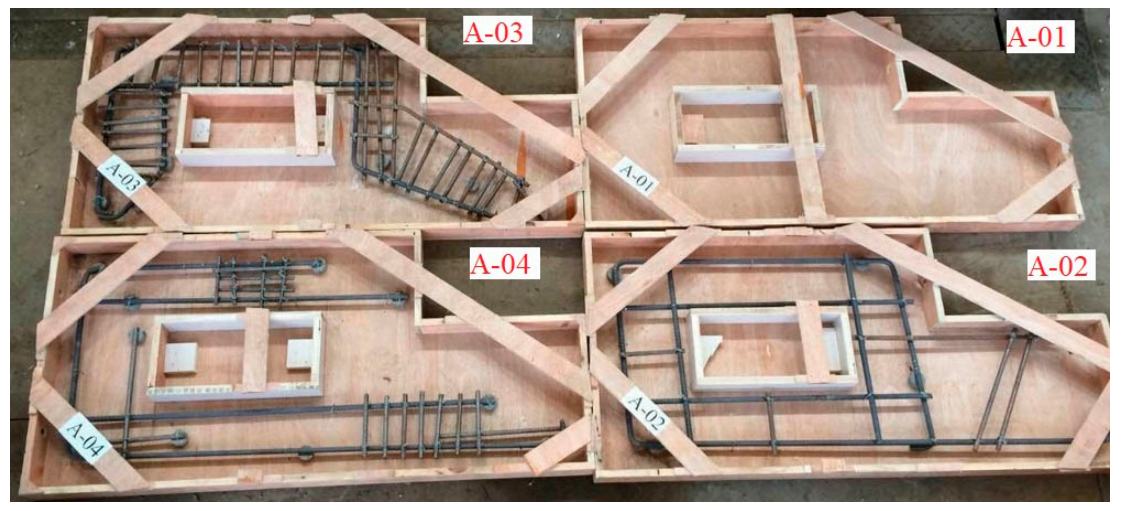

Figure 12. Framework and reinforcement cage of the Group A irregular concrete deep beam specimens.

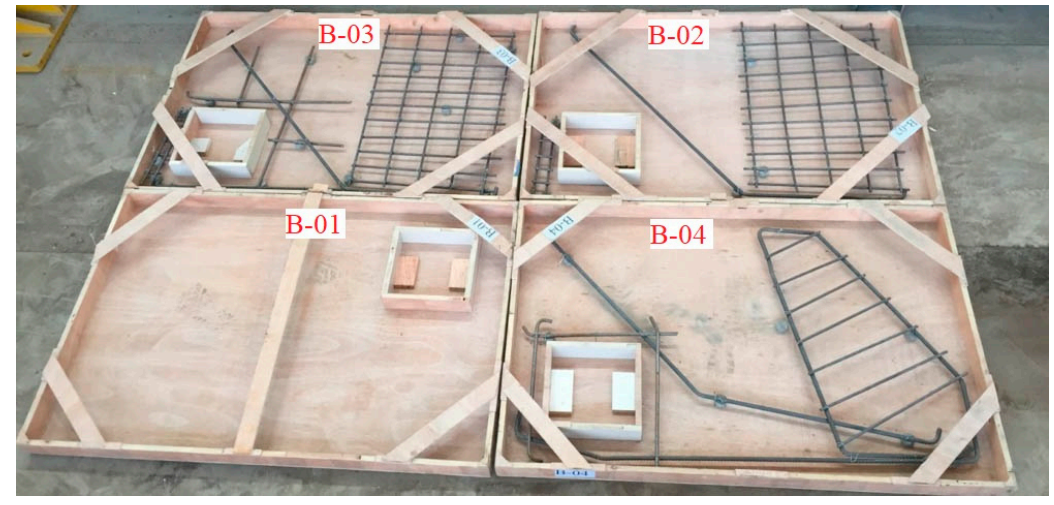

Figure 13. Framework and reinforcement cage of the Group B irregular concrete deep beam specimens.

In the test, the specimen was loaded by a reaction frame and a hydraulic jack, and a displacement gauge was used to measure the bottom deflection of the specimen at the midspan. The test data were collected by force sensor and a static information acquisition instrument. The test loading diagram is shown in Figure 14a. Because the geometries and sizes of the two groups of concrete deep beam specimens were different, the specimens were installed perpendicular to the plane of the reaction frame in order to facilitate the installation of the specimens and test equipment and to ensure the efficiency and safety of the tests, as shown in Figure 14b. Steel pads were placed between the jack and the top of the beam specimen as well as between the bottom of the specimen and the base.

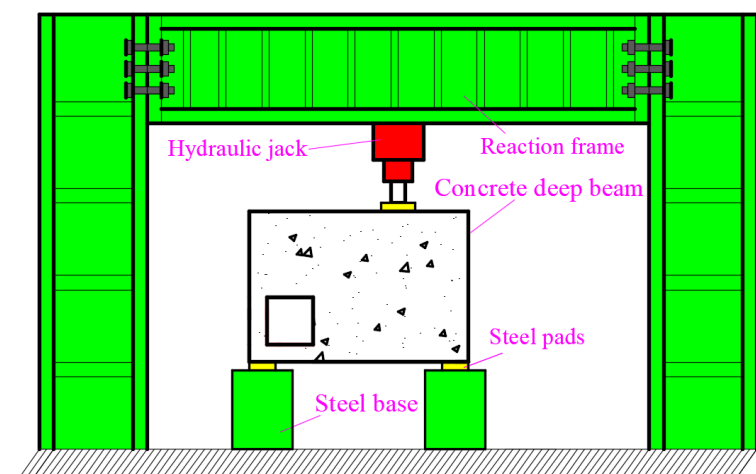

(a)

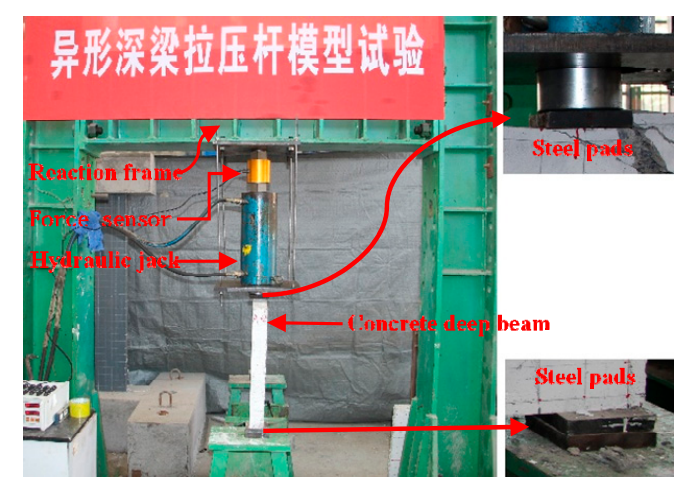

(b)

Figure 14. Diagrams of (a) test loading and (b) actual specimen installation. 
After being curried for 28 days, each specimen was subjected to stepped static loading using a 50-t hydraulic jack at an increment of $1 \mathrm{kN}$ per step, which was reduced to $0.5 \mathrm{kN}$ per step after the design load was reached. The load increment for the plain concrete specimens was $0.5 \mathrm{kN}$ at each step. Each step of the load was maintained for $0.5 \mathrm{~min}$. During the test, the cracking condition and morphology of the specimen were observed with a magnifying glass. The crack width was read using a hand-held crack observation apparatus, and the relevant test data and phenomena were recorded. A video camera was used to record the entire test process. To facilitate the observation of cracks in the specimen during the test, a layer of white paint was applied onto the side surfaces of the specimen in advance, drawing $50 \times 50 \mathrm{~mm}$ grids.

\subsection{Material Property Test}

The rebars used for the specimens were of grade HRB335 steel with diameters of $8 \mathrm{~mm}, 10 \mathrm{~mm}$, and $12 \mathrm{~mm}$. The tensile testing of the rebars was conducted as per the Tensile Testing of Metallic Materials Part 1: Method of Test at Room Temperature (GB/T 228.1-2010) [26]. The test data are shown in Table 1. Three sets of concrete test cubes $(150 \times 150 \times 150 \mathrm{~mm})$, which were reserved during the casting of the specimens, were cured for 28 days under standard conditions and then tested according to the Standard for Test Method of Mechanical Properties on Ordinary Concrete (GB/T 50081-2002) [27]. The measured compressive strength was $31.3 \mathrm{~N} / \mathrm{mm}^{2}$ and the elastic modulus was $3.10 \times 10^{4} \mathrm{~N} / \mathrm{mm}^{2}$.

Table 1. Mechanical properties of rebars.

\begin{tabular}{cccc}
\hline Diameter $(\mathbf{m m})$ & Yield Strength $f_{y, m} \mathbf{~ ( M P a ) ~}$ & Ultimate Strength $f_{u, m} \mathbf{~ M P a )}$ & Yield Strain $\varepsilon_{y, m}\left(\mathbf{1 0}^{-\mathbf{6}}\right)$ \\
\hline 8 & 332 & 420 & 1661 \\
10 & 340 & 511 & 1701 \\
12 & 497 & 626 & 2483 \\
\hline
\end{tabular}

\section{Test Results and Analysis}

\subsection{Crack Morphology}

Figure 15 shows the crack morphology of the Group A irregular concrete deep beam specimens at failure. In the figure, $C_{\mathrm{r} 1}, C_{\mathrm{r} 2}$, and $\mathrm{C}_{\mathrm{r} 3}$ was the sequence of crack initiation in the specimen. When the load at the top of the beam specimens in this group passed around the opening on both sides and was transferred to the two end supports, because the loading point was closer to the left support the stress on the left side of the force transfer path was relatively higher. The test phenomenon of the plain concrete specimen A-01 is shown in Figure 15a. The cracks $C_{r 1}$ and $C_{r 2}$ were the fracture cracks at the failure of the specimen, and the other cracks were those generated during the collision and removal of the specimens after fracture. According to the failure pattern, the weak regions of the specimens in this group were the region between the upper part of the opening and the loading point as well as the region between the lower left corner of the opening and the left support.

Because the stress was concentrated at the corners of the opening and the loading point, along with the proximity of the loading point to the upper left corner of the opening, the concrete between the upper left corner of the specimen and the loading point cracked first, i.e., crack $\mathrm{C}_{\mathrm{r} 1}$ was generated. When the loading effect became large, the diagonal crack $C_{\mathrm{r} 2}$ was formed between the lower left corner of the opening and the left support, and crack $\mathrm{C}_{\mathrm{r} 3}$ was generated due to the cracking at the bottom of the beam under tension. In the STM A- 02 of this specimen, there are only two horizontal ties (rebars) limiting the propagation of crack $\mathrm{C}_{\mathrm{r} 1}$, while there are no corresponding orthogonal bar members (rebars) to limit cracks $\mathrm{C}_{\mathrm{r} 2}$ and $\mathrm{C}_{\mathrm{r} 3}$. Eventually, specimen A-02 failed in shear along crack $\mathrm{C}_{\mathrm{r} 1}$, as shown in Figure 15b. 


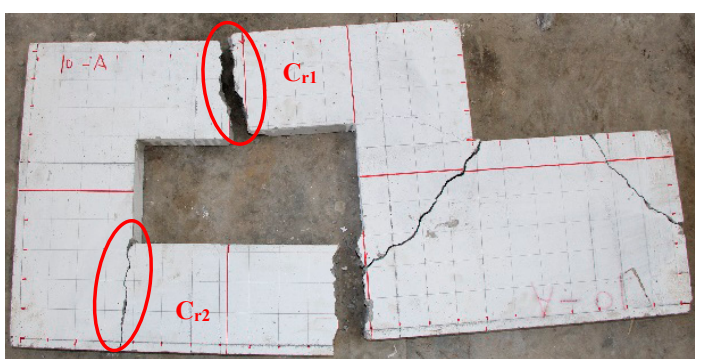

(a)

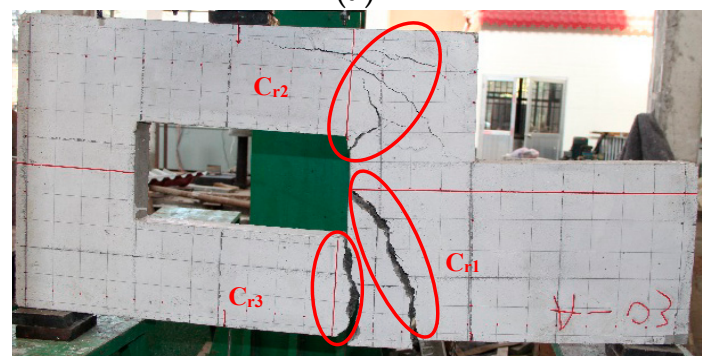

(c)

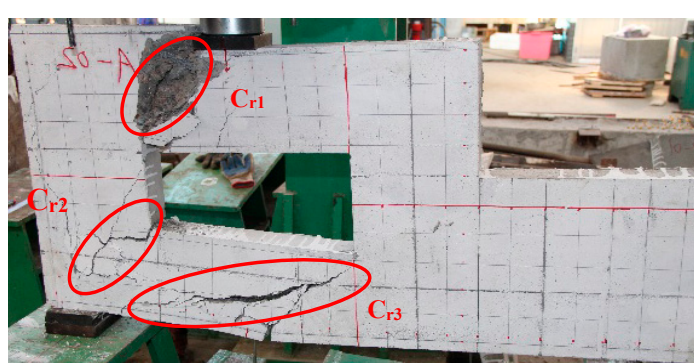

(b)

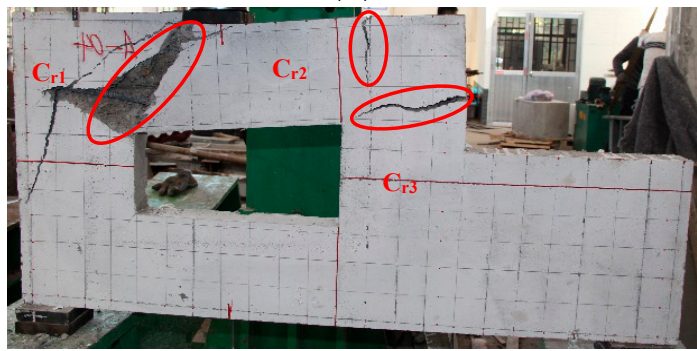

(d)

Figure 15. Failure patterns of Group A irregular concrete deep beam specimens: (a) specimen A-01; (b) specimen A-02; (c) specimen A-03; (d) specimen A-04.

It can be seen from the STM A-03 that there is no tie placed at the bottom of specimen A- 03 . Therefore, the concrete first cracked at the bottom of the beam at the midspan, and the crack propagated upward along the tie (rebar) on the right side of the opening until reaching the left side of the opening, i.e., generating crack $C_{r 1}$. Subsequently, crack $C_{r 2}$ was created at the upper right corner of the opening. Due to the restriction of the tie (rebar) at the upper right corner of the opening, crack $C_{\mathrm{r} 2}$ did not continue to grow. When the loading effect became large, the vertical crack $\mathrm{C}_{\mathrm{r} 3}$ was created between the lower right corner of the opening and the bottom of the beam at the midspan, and the width of this crack increased rapidly. Eventually, specimen A-03 failed due to the fracture of the concrete at cracks $\mathrm{C}_{\mathrm{r} 1}$ and $\mathrm{C}_{\mathrm{r} 3}$, as shown in Figure 15c.

In the STM A-04 the bar members are sparsely arranged and ties (rebars) are provided at the bottom of the specimen, the upper part of the opening, and the lower left corner of the opening to limit or delay the generation of cracks. A diagonal crack $C_{r 1}$ was first formed in the specimen between the upper left corner of the opening and the loading point. As the diagonal crack $C_{r 1}$ propagated continuously, cracks $C_{r 2}$ and $C_{r 3}$ were formed in the upper right part of specimen A-04, which eventually failed in shear along crack $C_{r 1}$. Its failure pattern was similar to that of specimen A-02, as shown in Figure $15 \mathrm{~d}$.

Figure 16 shows the crack morphology of the Group B irregular concrete deep beam specimens at failure. The plain concrete specimen B-01 fractured instantaneously from the left support diagonally to the loading point, as shown by cracks $\mathrm{C}_{\mathrm{r} 1}$ and $\mathrm{C}_{\mathrm{r} 2}$ in Figure 16a. The other cracks were generated due to the collision and removal of the specimen after fracture. According to the failure pattern of specimen B-01, the weak region of the specimens in this group under the load were the region between the left support and the lower left corner of the opening, as well as the region between the upper right corner of the opening and the loading point.

In the STM B-02, no full-length tie (rebar) is placed at the bottom of the specimen; only a diagonal tie was placed at the upper right corner of the opening in the left half of the specimen, and a bottle-shaped strut (orthogonal grid rebars) was placed in the right half of the specimen. Therefore, the concrete at the upper right corner of the opening on the left side of specimen B-02 cracked first due to a stress concentration, and crack $C_{r 1}$ propagated diagonally toward the loading point. This crack was constrained by the diagonal tie (rebar) in the upper right part of the opening. As the load increased, the tensile stress at the bottom of the specimen was high, and the concrete at the bottom of the opening cracked, generating cracks $C_{r 2}$ and $C_{r 3}$. Specimen B-02 failed due to the fracture of the concrete at 
the bottom of the opening along cracks $\mathrm{C}_{\mathrm{r} 2}$ and $\mathrm{C}_{\mathrm{r} 3}$, when the concrete at the loading point was severely crushed.

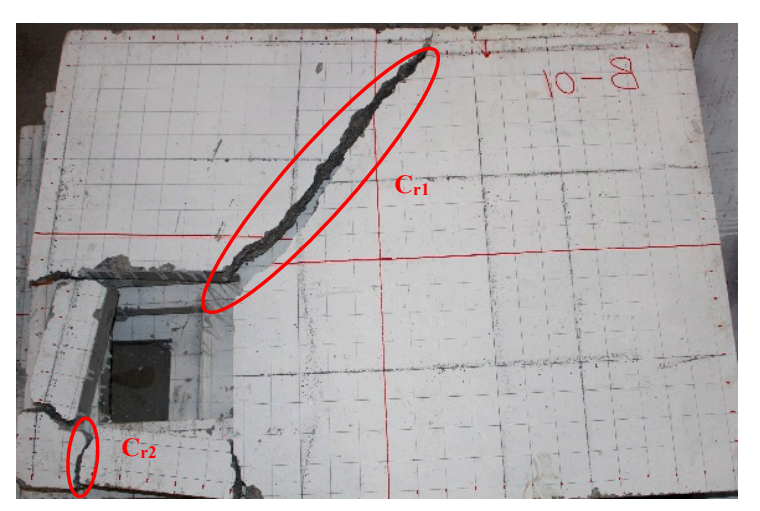

(a)

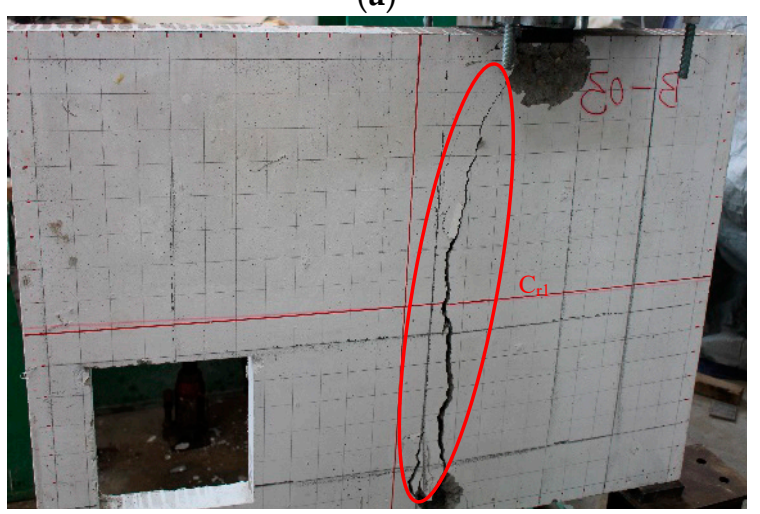

(c)

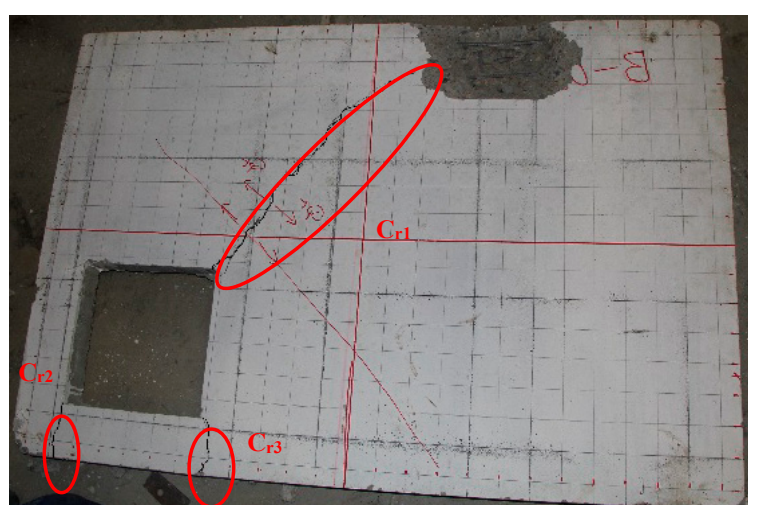

(b)

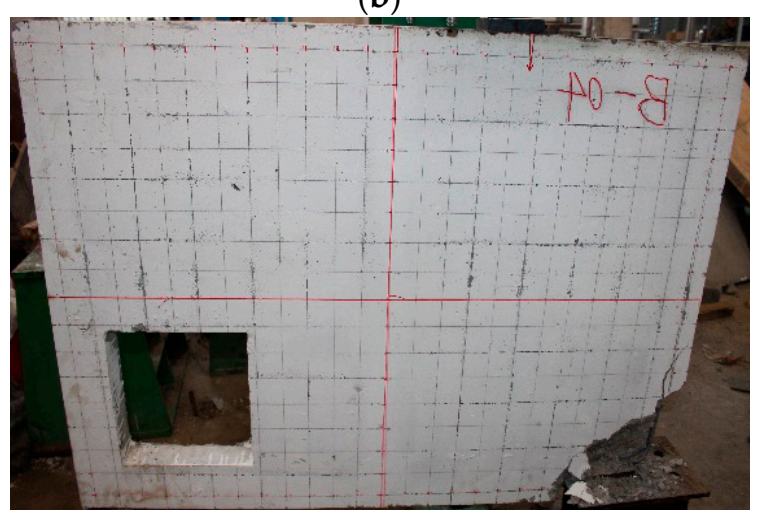

(d)

Figure 16. Failure patterns of the Group B irregular concrete deep beams: (a) specimen B-01; (b) specimen B-02; (c) specimen B-03; (d) specimen B-04

The STM B-03 was added with orthogonal ties (rebars) at the upper right corner of the opening, and full-length ties (rebars) were placed at the bottom of the beam. However, the STM B-03 had relatively poor integrity, i.e., the left and right halves of the model were only connected by horizontal ties at the bottom. Under the load, because the weak region between the left support and the loading point was strengthened by the corresponding ties (rebars), the concrete at the bottom of beam specimen B-03 cracked under tension, and crack $\mathrm{C}_{\mathrm{r} 1}$ propagated upward along the left edge of the bottle-shaped strut (orthogonal grid rebars) on the right side until reaching the loading point. As the load increased, the width of crack $C_{r 1}$ increased continuously. Specimen B-03 eventually fractured along the crack into the left and right parts, as shown in Figure 16c.

In the STM B-04, both diagonal and horizontal ties were placed in the weak regions between the lower left corner of the opening and the left support, as well as between the upper right corner of the opening and the loading point to limit or delay the formation of cracks. The full-length horizontal ties (rebars) at the bottom of the beam and the diagonal ties (rebars) extending from the right support to the upper left corner of the specimen increased the integrity of the STM. No visible cracks were observed in specimen B-04 below $95 \mathrm{kN}$. As the load increased, the concrete of the specimen at the right support began to collapse. The specimen eventually became unstable due to a local failure at the right support, as shown in Figure 16d, which was mainly attributed to the thin concrete cover of the scaled specimen.

\subsection{Mechanical Properties}

The test results of the two groups of irregular concrete deep beam specimens are shown in Table 2. $P_{c}$ is the cracking load of the specimen; $P_{d}$ is the design load of the specimen; $P_{u}$ is the ultimate 
load-carrying capacity of the specimen; $C_{W}$ is the maximum crack width of the specimen under the design load; $\Delta_{\mathrm{d}}$ is the midspan deflection of the bottom of the beam specimen under the design load; and $\Delta_{\mathfrak{u}}$ is the deflection of the specimen when its ultimate load-carrying capacity is reached. The load-deflection curves are shown in Figure 17.

Table 2. Test results of the mechanical properties of different specimens.

\begin{tabular}{cccccccc}
\hline Specimen & $\mathbf{P}_{\mathbf{c}}(\mathbf{k N})$ & $\mathbf{P}_{\mathbf{d}}(\mathbf{k N})$ & $\mathbf{P}_{\mathbf{u}}(\mathbf{k N})$ & $\mathbf{C}_{\mathbf{w}}(\mathbf{m m})$ & $\boldsymbol{\Delta}_{\mathbf{d}}(\mathbf{m m})$ & $\boldsymbol{\Delta}_{\mathbf{u}}(\mathbf{m m})$ & $\mathbf{P}_{\mathbf{u}} / \mathbf{P}_{\mathbf{d}}$ \\
\hline A-01 & 5.5 & 40 & 5.5 & - & - & 0.75 & 0.14 \\
A-02 & 30 & 40 & 55 & 0.4 & 2.25 & 5.70 & 1.38 \\
A-03 & 26 & 40 & 45 & 0.5 & 2.80 & 4.30 & 1.13 \\
A-04 & 33 & 40 & 59 & 0.3 & 2.10 & 5.60 & 1.48 \\
B-01 & - & 100 & 22 & - & - & 0.60 & 0.22 \\
B-02 & 85 & 100 & 120 & 0.3 & 2.69 & 3.98 & 1.20 \\
B-03 & 91 & 100 & 136 & 0.4 & 2.17 & 3.71 & 1.36 \\
B-04 & 95 & 100 & 141 & - & 2.54 & 4.73 & 1.41 \\
\hline
\end{tabular}

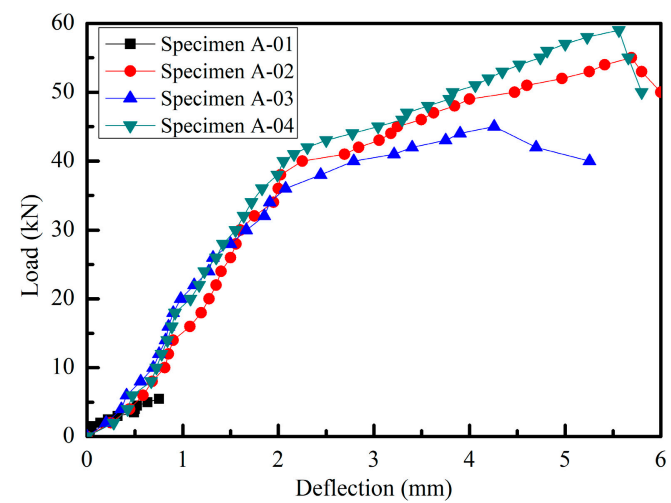

(a)

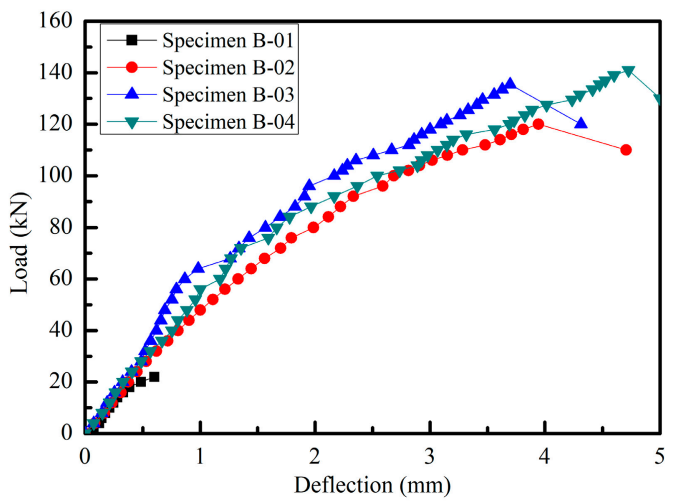

(b)

Figure 17. Load-deflection curves of the specimens: (a) Group A irregular concrete deep beam specimens; (b) Group B irregular concrete deep beam specimens.

Table 2 and Figure 17 show that except for the plain concrete specimens A-01 and B-01, all specimens had an ultimate load-carrying capacity that exceeded the corresponding design load, verifying the effectiveness of the STM design method. In the Group A irregular concrete deep beam specimens, specimen A-04 had the largest cracking load and ultimate load-carrying capacity, and its midspan deflection at the bottom of the beam under the design load was the smallest. Specimen A-03 had the smallest ultimate load-carrying capacity, and its midspan deflection at the bottom of the beam at the time of failure was the smallest. Specimen A-02 had the largest midspan deflection at the bottom of the beam at the time of failure, followed by specimen A-04. The $\mathrm{P}_{\mathrm{u}} / \mathrm{P}_{\mathrm{d}}$ of specimen A-04 was $10 \%$ and $35 \%$ larger than that of specimens A-02 and A- 03 , respectively. In the Group B irregular concrete deep beams, specimen B-04 had the largest cracking load $(95 \mathrm{kN})$ and ultimate load-carrying capacity $(141 \mathrm{kN})$, followed by specimen B-03. Additionally, specimen B-04 had the smallest crack width under the design load, and its midspan deflection at the bottom of the beam was between those of specimens B-02 and B-03. The Pu/Pd of specimen B- 04 was $21 \%$ and 5\% larger than that of specimens B-02 and B-03, respectively.

The variation trends of the load-deflection curves of the irregular concrete deep beam specimens in the two groups are essentially the same. The load-deflection curves of specimens A-02 and A-04 are closer, as are load-deflection curves of specimens B-02 and B-04. At the initial stage of loading, that is, from the beginning of loading to the time when cracks occurred in the specimens, the concrete resisted most of the load, resulting in essentially the same load-deflection curves of different specimens. However, for concrete deep beams in the elastic stage, due to the large shear deformation and 
coexistence of the beam action and arch action, the stress in the concrete compression zone also exhibited a nonlinear distribution. With the generation and development of cracks, the stress in the specimen was redistributed, and the rebar stress gradually increased, forming a "tie", which together with the concrete soffit between the loading point and the supports at both ends constituted a "tied arch" system. The difference in the load-deflection curves of different specimens was caused by the different reinforcement designs guided by different STMs.

\subsection{Amount of Steel Used}

To better assess the economic feasibility of the reinforcement design guided by different optimal STMs, a reinforcement design evaluation index, namely, reinforcement efficiency, was introduced. The calculation equation is as follows:

$$
\rho_{s}=\frac{P_{u}-P_{0}}{W_{s}}
$$

where $P_{0}$ is the ultimate load-carrying capacity of a plain concrete specimen $(\mathrm{kN})$; and $\mathrm{W}_{\mathrm{s}}$ is the amount of steel used for the specimen $(\mathrm{kg})$.

Figure 17 shows the amount of steel used and the reinforcement efficiency of each irregular concrete deep beam specimen in the group. It can be seen from Figure 18 that for the irregular concrete deep beams in Group A specimen A-04 used the least amount of steel $(4.74 \mathrm{~kg})$, which was $7 \%$ and $26 \%$ less than that of specimens A-02 and A-03, respectively. Accordingly, specimen A-04 had the highest reinforcement efficiency $(11.29 \mathrm{kN} / \mathrm{kg})$, which was $16 \%$ and $83 \%$ higher than that of specimens A-02 and A-03, respectively. For the irregular concrete deep beam specimens in Group B, specimen B-04 used the least amount of steel $(4.36 \mathrm{~kg})$, which was $22 \%$ and $41 \%$ less than that of specimens B- 02 and B-03, respectively. Accordingly, specimen B-04 had the highest reinforcement efficiency $(32.33 \mathrm{kN} / \mathrm{kg})$, which was $84 \%$ and $111 \%$ higher than that of specimens B-02 and B- 03 , respectively. That is, the rebars were most efficiently used in specimens A- 04 and B-04, which were thus the most economically feasible.

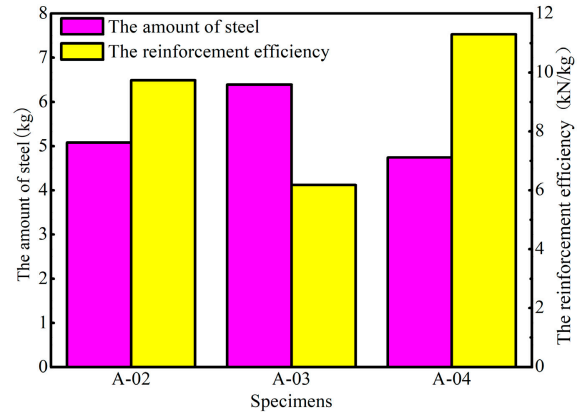

(a)

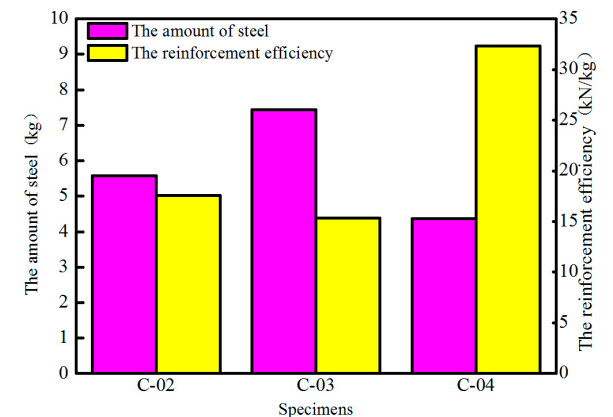

(b)

Figure 18. Amount of steel used and the reinforcement efficiency: (a) Group A irregular concrete deep beam specimens; (b) Group B shaped concrete deep beam specimens.

\section{Conclusions}

An experimental study was conducted on the strut-and-tie model (STM) of irregular concrete deep beams. The main results are summarized as follows.

The typology of STM has an important impact on the mechanical performance, failure pattern, and economic feasibility of the reinforcement design of irregular concrete deep beams. An accurate and reasonable optimal STM plays a decisive role in improving the design and reducing the cost of irregular concrete deep beams.

The optimal STMs constructed in this study (STM A-04 and STM B-04) have significant advantages in improving the load-carrying capacity and reducing the amount of steel used in structural members; they are also beneficial in delaying the crack formation in structural members and reducing the crack width. The ultimate load-carrying capacities of the two irregular concrete deep beams (specimens 
A-04 and B-04) designed using the STMs in this study were both more than $41 \%$ higher than the corresponding design load, proving the reliability and ability of these STMs in generating conservative designs, which has a practical guiding significance for the reinforcement design of irregular concrete deep beams.

The STM design method is simple, efficient and can effectively solve the problem of the reinforcement design for the D-regions of irregular concrete deep beams. It is suggested that the distribution reinforcement be placed at the loading point and near the supports to not only prevent a local failure but also be conducive to the force transfer and diffusion of the structural members while improving their ductility.

Author Contributions: Methodology, L.W.; software, J.Z.; validation, H.C. and J.Z.; investigation, H.C.; data curation, H.C.; writing-original draft preparation, H.C. and L.W.; writing-review and editing, H.C.; supervision, L.W.; funding acquisition, H.C. and J.Z.

Funding: This research was funded by Projects of Science and Technology Innovation Fund for graduate students of Shandong University of Science and Technology (No. SDKDYC180213), National Natural Science Foundation of China (No. 51808323), Natural Science Foundation of Shandong Province (No. ZR2017BEE017) and Scientific Research Foundation of Shandong University of Science and Technology for Recruited Talents (No. 2017RCJJ049).

Conflicts of Interest: The authors declare no conflict of interest.

\section{References}

1. Smarzewski, P. Analysis of Failure Mechanics in Hybrid Fibre-Reinforced High-Performance Concrete Deep Beams with and without Openings. Materials 2019, 12, 101. [CrossRef] [PubMed]

2. Marti, P. Basic tools of reinforced concrete beam design. J. Am. Concr. Inst. 1985, 82, 46-56.

3. Schlaich, J.; Schäfer, K. Towards a consistent design of reinforced concrete structures. IABSE Congress Report $=$ Rapport du Congrès AIPC $=$ IVBH Kongressbericht, Band (Jahr) 1984, 12, 887-894. [CrossRef]

4. Breen, J.E.; Burdet, O.; Roberts, C.; Sanders, D.; Wollmann, G. Anchorage Zone Reinforcement for Post-Tensioned Concrete Girders; NCHRP Report; Transportation Research Board: Washington, DC, USA, 1994; Available online: http://onlinepubs.trb.org/Onlinepubs/nchrp/nchrp_rpt_356.pdf (accessed on 21 August 2019).

5. Chen, B.S.; Hagenberger, M.J.; Breen, J.E. Evaluation of strut-and-tie modeling applied to dapped beam with opening. ACI Struct. J. 2002, 99, 445-450.

6. Novak, L.C.; Sprenger, H. Example 4: Deep Beam with Opening. In Examples for the Design of Structural Concrete with Strut-and-Tie Models, Proceedings of the ACI Fall Convention, Phoenix, AZ, USA, 27 October-1 November 2002; American Concrete Institute: Farmington Hills, MI, USA, 2002; pp. 129-143. Available online: http://worldcat.org/isbn/0870310860 (accessed on 21 August 2019).

7. American Concrete Institute. Building Code Requirements for Structural Concrete (ACI 318-02) and Commentary; ACI: Farmington Hills, MI, USA, 2002.

8. Ye, L.P.; Meng, J.; Wang, Y.H. Application of Strut-and-tie Model in Design of Reinforced Concrete Deep Beams. J. Arch. Civ. Eng. 2009, 26, 81-86.

9. American Concrete Institute. Building Code Requirements for Structural Concrete (ACI 318M-05) and Commentary; ACI: Farmington Hills, MI, USA, 2005.

10. The State Standard of the People's Republic of China. Code for Design of Concrete Structures (GB50010-2010); China Architecture \& Building Press: Beijing, China, 2010.

11. American Association of State Highway and Transportation Officials. AASHTO LRFD Bridge Design Specifications; American Association of State Highway and Transportation Officials: Washington, DC, USA, 2007.

12. Deutsche Norm, Concrete, Reinforced and Prestressed Concrete Structures-Part 1:3 Design and Construction, Corrigenda to DIN 1045-1:2001-07; German Institute for Standardisation (Deutsches Institut für Normung): Berlin, Germany, 2008.

13. Canadian Standards Association (CSA). Design of Concrete Structures for Buildings (CAN3-A23.3-M84); CSA: Toronto, ON, Canada, 1984.

14. Xie, Y.M.; Steven, G.P. A simple evolutionary procedure for structural optimization. Comput. Struct. 1993, 49, 885-896. [CrossRef] 
15. Yang, X.Y.; Xie, Y.M.; Steven, G.P.; Querin, O.M. Bidirectional Evolutionary Method for Stiffness Optimization. AIAA J. 1999, 37, 1483-1488. [CrossRef]

16. Herranz, U.P.; María, H.S.; Gutiérrez, S.; Riddell, R. Optimal Strut-and-Tie Models Using the Full Homogenization Optimization Method. ACI Struct. J. 2012, 109, 605-614.

17. Victoria, M.; Querin, O.M.; Martí, P. Generation of strut-and-tie models by topology design using different material properties in tension and compression. Struct. Multidiscip. Optim. 2011, 44, 247-258. [CrossRef]

18. Muttoni, A.; Ruiz, M.F.; Niketic, F. Design versus assessment of concrete structures using stress fields and strut-and-tie models. ACI Struct. J. 2015, 112, 605-616. [CrossRef]

19. Ali, M.A.; White, R.N. Formulation of optimal strut-and-tie models in design of reinforced concrete structures. Spec. Publ. 2000, 193, 979-998.

20. Wang, C.; Huang, H.; Liu, B.; Xiao, J. Reinforcement design and nonlinear finite element analysis of concrete deep beam with abnormal opening. Build. Struct. 2015, 45, 525-529.

21. Huang, X.; Xie, Y.M. Evolutionary Topology Optimization of Continuum Structures: Methods and Applications; John Wiley and Sons Ltd.: Chichester, West Sussex, UK, 2010; pp. 17-38.

22. Sun, X.F.; Yang, J.; Xie, Y.M.; Huang, X.; Zuo, Z.H. Topology Optimization of Composite Structure Using Bi-Directional Evolutionary Structural Optimization Method. Procedia Eng. 2011, 14, 2980-2985. [CrossRef]

23. Ley, M.T.; Riding, K.A.; Bae, S.; Breen, J.E. Experimental Verification of Strut-and-Tie Model Design Method. ACI Struct. J. 2007, 104, 749-755.

24. Maxwell, B.S.; Breen, J.E. Experimental evaluation of strut-and-tie model applied to deep beam with opening. ACI Struct. J. 2000, 97, 142-148.

25. American Concrete Institute. Building Code Requirements for Structural Concrete (ACI 318-08) and Commentary; American Concrete Institute: Farmington Hills, MI, USA, 2008.

26. The State Standard of the People's Republic of China. Tensile Testing of Metallic Materials Part 1: Method of Test at Room Temperature (GB/T228.1-2010); China Architecture \& Building Press: Beijing, China, 2010.

27. The State Standard of the People's Republic of China. Standard for Test Method of Mechanical Properties on Ordinary Concrete (GB/T50081-2002); China Architecture \& Building Press: Beijing, China, 2002.

(C) 2019 by the authors. Licensee MDPI, Basel, Switzerland. This article is an open access article distributed under the terms and conditions of the Creative Commons Attribution (CC BY) license (http://creativecommons.org/licenses/by/4.0/). 